\title{
Intraflagellar transport complex structure and cargo interactions
}

\author{
Sagar Bhogaraju', Benjamin D Engel ${ }^{2}$ and Esben Lorentzen ${ }^{1 *}$
}

\begin{abstract}
Intraflagellar transport (IFT) is required for the assembly and maintenance of cilia, as well as the proper function of ciliary motility and signaling. IFT is powered by molecular motors that move along the axonemal microtubules, carrying large complexes of IFT proteins that travel together as so-called trains. IFT complexes likely function as adaptors that mediate interactions between anterograde/retrograde motors and ciliary cargoes, facilitating cargo transport between the base and tip of the cilium. Here, we provide an up-to-date review of IFT complex structure and architecture, and discuss how interactions with cargoes and motors may be achieved.
\end{abstract}

Keywords: Intraflagellar transport, Cilium, IFT, IFT complex, IFT cargo

\section{Review}

Twenty years ago, Kozminsky and colleagues first described intraflagellar transport (IFT) as a motility in the Chlamydomonas flagellum that is distinct from flagellar beating [1]. IFT trains were observed by electron microscopy to be linear arrays of electron-dense particles spanning the distance between the outer doublet microtubules and the flagellar membrane. Following the discovery of IFT, biochemical purification of native IFT complexes from Chlamydomonas revealed 15 polypeptides that organize into two IFT sub-complexes, known as IFT-A and IFT-B [2,3]. IFT polypeptide orthologues were also found in mice $[4,5]$, suggesting that IFT proteins are largely conserved. Subsequent studies identified additional IFT proteins, bringing the current IFT protein count up to 20 [5-11]. Mutations in IFT proteins have been shown to cause several ciliopathies [12-22]. The genetic deletion of an entire IFT protein often leads to a general defect in cilia assembly (presumably due to IFT complex disruption), making it difficult to assess the specific functions of individual IFT proteins from mutant phenotypes alone [8,23-31]. Thus, a more complete understanding of IFT protein function in ciliogenesis, including cargo and motor interactions, will require detailed molecular and structural studies of IFT complexes.

\footnotetext{
* Correspondence: lorentze@biochem.mpg.de

'Department of Structural Cell Biology, Max-Planck-Institute of Biochemistry, Am Klopferspitz 18, D-82152 Martinsried, Germany

Full list of author information is available at the end of the article
}

Structural investigations of IFT complexes have been limited so far to electron tomographic reconstructions of IFT particles in situ [32] and the high-resolution crystal structure of the IFT25/27 sub-complex [33]. However, the overall architecture of the IFT complex is starting to take shape, largely as a result of biochemical studies $[25,26,34,35]$. In this review we attempt to partition IFT proteins into principal domains (PD) and auxiliary domains (AD) based on the current literature. Whereas PD mutations lead to IFT complex destabilization with general ciliogenesis phenotypes, $\mathrm{AD}$ mutations may facilitate the study of specific IFT protein functionality. Such a division may assist in designing experiments to probe the roles of individual IFT proteins in cilium formation and function.

\section{The intraflagellar transport complex: a protein-protein interaction platform?}

Bioinformatic analysis of IFT proteins predicts a large number of potential protein-protein interaction domains such as tetratrico peptide repeats (TPRs), WD40 $\beta$ propellers and coiled-coils [36-39]. Strikingly, with the exception of the two small GTPases IFT22 and IFT27, none of the other IFT proteins are predicted to have enzymatic activity. The prediction is thus that the IFT complex forms a large platform with multiple protein interaction sites that allows binding to molecular motors as well as ciliary cargoes.

Structure prediction using the HHpred server [40] revealed that most IFT proteins likely contain multiple

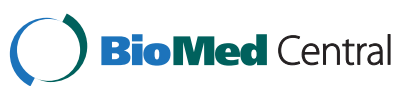

(c) 2013 Bhogaraju et al.; licensee BioMed Central Ltd. This is an Open Access article distributed under the terms of the Creative Commons Attribution License (http://creativecommons.org/licenses/by/2.0), which permits unrestricted use, distribution, and reproduction in any medium, provided the original work is properly cited. 
domains [39]. Limited proteolysis on in vitro reconstituted IFT complexes demonstrated that only a subset of these domains are required for IFT complex formation, indicating that numerous domains are available to interact with other binding partners such as ciliary cargoes or motors [35]. Most IFT proteins can therefore be divided into PDs and ADs as described above (Figure 1). The main function of PDs is to provide structural stability, and thus they are well conserved in protein sequence to ensure the integrity of IFT complex formation. However, most IFT protein domains not required for IFT complex stability (the ADs) are also highly conserved in sequence, likely reflecting important functions such as ciliary cargo interactions. A good example of the PD/AD division is IFT46, a core component of IFT-B, where only the IFT46 C-terminal domain is required for the stability of the IFT complex via interaction with the C-terminal domain of IFT52 [25,35], while the $\mathrm{N}$-terminal domain is involved in the ciliary transport of outer dynein arms (ODAs) [24,41,42]. Similarly, IFT52 interacts directly with at least four different IFT proteins (IFT74/81, IFT46, IFT70 and IFT88) via its middle and C-terminal domains, while the conserved $\mathrm{N}$-terminal domain is not required for IFT-B complex formation and thus likely constitutes an $\mathrm{AD}[25,35]$. The N-terminal domain of IFT74 is also not required for IFT-B core complex formation and may constitute an AD [35]. The peripheral IFT proteins IFT54 and IFT57 both have predicted coiled-coil domains at the C-termini that interact with IFT20 [43-45]. However, the N-terminal regions of both IFT57 and IFT54 are predicted to be alpha helical domains that could constitute ADs [39] (Figure 1).

It is important to note that while the $\mathrm{PD} / \mathrm{AD}$ boundary of some IFT proteins is well defined, this is not the case for all IFT proteins. In particular, TPR domain-containing proteins such as IFT70 and IFT88 may possess a single structural module that functions as both a PD and an $\mathrm{AD}$ (Figure 1). Another example is IFT25 and the small GTPase IFT27, which form a stable heterodimer that can be considered as a single structural module [33]. While the IFT25/27 heterodimer directly binds the "core" IFT74/ 81 complex [35], it also contains a conserved surface patch in close proximity to the GTPase active site of IFT27 that may interact with a yet unidentified binding partner in a nucleotide-state-dependent manner [33]. Interestingly, IFT25 knockout mice show no ciliogenesis defects but die at birth due to sonic hedgehog (Shh) signaling dysfunction [46]. This indicates that the IFT25/27 sub-complex is not needed for the stability of the IFT complex and may function in the IFT of Shh signaling components. Additionally, IFT25 and IFT27 are not present in Caenorhabditis elegans and Drosophila melanogaster [10,38]. Thus, IFT25/ 27 may be defined as an AD module (Figure 1).

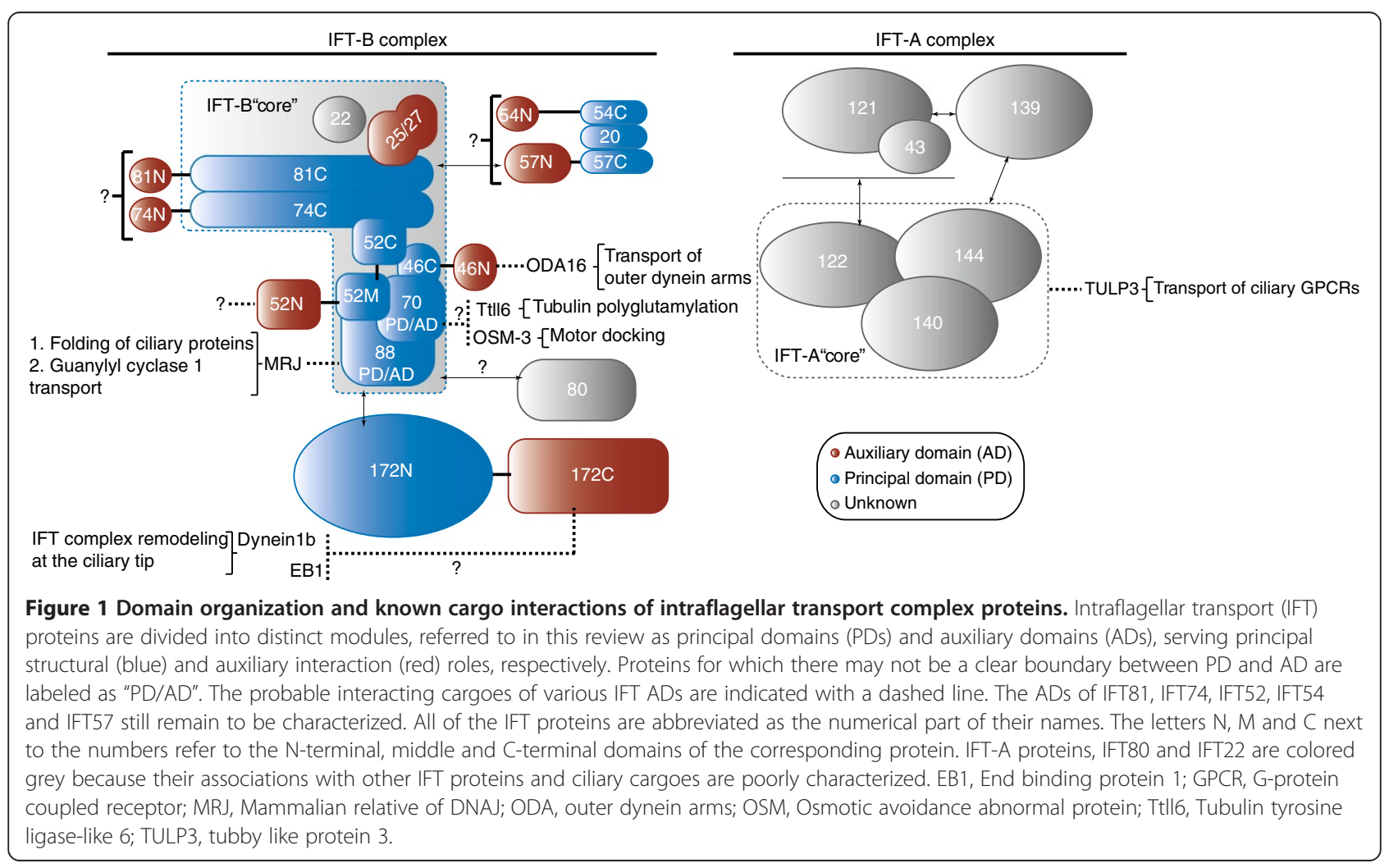




\section{Ciliary targeting sequences}

Proteins that localize to subcellular compartments such as mitochondria or the nucleus have distinct sequence motifs (known as cellular ZIP codes) that specifically target them to their respective organelles [47]. Although the cilium is topologically equivalent to the cytoplasm, there are transition zone structures at the ciliary base that prevent random diffusion of both soluble and membrane-bound macromolecules into the cilium [48-56]. As approximately 600 different proteins reside within the cilium [57], it seems likely that one or more ZIP codes also exist for ciliary targeting [58].

\section{The $(F / Y / W) R$ motif}

One of the earliest reports of a ciliary targeting sequence (CTS) was the identification of a phenylalanine-arginine (FR) motif in the C-terminal cytoplasmic regions of $C$. elegans olfactory receptor proteins ODR-10 and STR-1 [59]. Deletion of this FR motif from ODR-10 and STR-1 resulted in dispersed localization of the receptors in the cell body, indicating that the FR motif is required for ciliary localization. This $(\mathrm{F} / \mathrm{Y} / \mathrm{W}) \mathrm{R}$ motif is conserved in several ciliary G-protein coupled receptors (GPCRs) including somatostatin receptor 3 (SSTR3), serotonin receptor 6 (5-HTR6) and rhodopsin, suggesting a widely prevalent and conserved mechanism of targeting GPCRs to the cilium [59]. A similar motif in mammalian Smoothened (smo) was also shown to be required for localization to the cilium [60]. However, several GPCRs that contain $(\mathrm{F} / \mathrm{Y} / \mathrm{W}) \mathrm{R}$ motifs do not localize to cilia, indicating that the ciliary targeting of GPCR proteins is more complex. Inspection of the rhodopsin crystal structure reveals that an equivalent residue (F313 of alpha-helix VIII) [61], identified to be a part of the $(\mathrm{F} / \mathrm{Y} / \mathrm{W}) \mathrm{R}$ motif in the other GPCRs, is buried within the hydrophobic core of the protein and hence may be necessary for proper protein folding. This suggests that mislocalization of ciliary GPCRs upon mutation of the $(\mathrm{F} / \mathrm{Y} / \mathrm{W}) \mathrm{R}$ motif may be an effect of compromised structural integrity of the GPCR fold rather than a primary defect in ciliary targeting. It is thus not surprising that different CTSs have been identified in several ciliary GPCRs including SSTR3, 5-HTR6 and rhodopsin, as described in the following sections.

\section{The $A x(S / A) x Q$ motif}

Comparative sequence conservation analysis of ciliary and non-ciliary GPCRs revealed a different consensus amino acid sequence, $\mathrm{Ax}(\mathrm{S} / \mathrm{A}) \mathrm{xQ}$ (where $\mathrm{x}$ denotes any amino acid), in the third intracellular loop of ciliary GPCRs [62]. Mutating the conserved A or Q in this motif resulted in the mislocalization of SSTR3 and 5-HTR6 [62]. Conversely, the chimeric non-ciliary GPCR Htr7 with this motif inserted into its third intracellular loop showed markedly increased ciliary localization [62]. Recently, a similar signal sequence was found in the third intracellular loop of another ciliary GPCR, melanin-concentrating hormone receptor 1 [63]. These results indicate that the $\mathrm{Ax}$ (S/A)xQ motif is both necessary and sufficient for the localization of these GPCRs. The mouse GPCR Gpr161 was also shown to contain a CTS ((I/V)KARK) in its third intracellular loop that is both necessary and sufficient for localization to cilia [64]. Interestingly, this CTS is different from the $\operatorname{Ax}(\mathrm{S} / \mathrm{A}) \mathrm{xQ}$ motif described above, suggesting that the third intracellular loops of different GPCRs may contain distinct sequence motifs that confer ciliary localization.

\section{The VxPx motif}

In addition to the $(\mathrm{F} / \mathrm{Y} / \mathrm{W} /) \mathrm{R}$ motif described above, rhodopsin was shown to contain a VxPx motif at its cytoplasmic C-terminus that serves as a CTS $[65,66]$. The $\mathrm{Ca}^{2+}$ ion channel polycystin-2 (PC2) also has an $\mathrm{N}$-terminal RVxP motif that is required for its ciliary localization [67], and polycystin-1 (PC1), a direct interacting partner of $\mathrm{PC} 2$, contains a similar CTS (KVHPSST) at its cytoplasmic C-terminus [68]. Thus, PC1, $\mathrm{PC} 2$ and rhodopsin share a common (K/R/Q) VxPx motif required for ciliary localization.

\section{The KRKK NLS-like motif}

Compared to the CTSs of membrane proteins, very little is known about the ciliary targeting of soluble proteins. Although there is increasing evidence that tubulin, ODAs and retrograde dynein motors are IFT cargoes $[24,69,70]$, it is unknown how these soluble proteins are recognized by the IFT machinery. Recently, however, the KRKK motif was identified as a CTS in the C-terminal tail of the homodimeric anterograde IFT motor KIF-17 [71]. Remarkably, this CTS is very similar to the nuclear localization signal (NLS) recognized by importin- $\beta 2$. Both importin- $\beta 2$ and a Ran-GTP gradient, which are key to nucleo-cytoplasmic transport, also appear to be required for ciliary entry of KIF-17 [71,72]. Furthermore, retinitis pigmentosa 2 was also shown to depend on interaction with importin- $\beta 2$ for ciliary entry [73]. Another study identified certain nucleoporins at the base of the cilium by immunofluorescence and immunogold electron microscopy [51], although this result remains to be verified. It is unclear at this point whether NLSmediated ciliary entry is applicable to a broad range of other ciliary proteins.

\section{How are ciliary targeting sequences recognized by the intraflagellar transport machinery?}

Several lines of evidence suggest that many of the above mentioned membrane proteins are transported into the 
cilium as IFT cargoes. Rhodopsin requires transport into the outer segment (OS) of photoreceptor cells via the connecting cilium [74], and mutations in IFT proteins or motors have been shown to affect the transport of rhodopsin, indicating a critical role for IFT in this process $[4,43,75,76]$. The ciliary membrane Transient Receptor Potential Vanilloid (TRPV) channels OSM-9 and OCR-2 undergo IFT-like movements within the cilia of $C$. elegans sensory neurons [77], and a fraction of Chlamydomonas $\mathrm{PC} 2$ also undergoes directed movement that is likely driven by IFT [78]. Furthermore, in Chlamydomonas IFT has been shown to be physically coupled to the movement of flagellar membrane glycoproteins in a $\mathrm{Ca}^{2+}$-dependent manner [79]. However, a direct link between the CTSs of membrane proteins and their association with the IFT complex has not yet been demonstrated.

Mutations in IFT-A proteins are known to affect the transport of several membrane proteins including certain ciliary GPCRs $[64,80,81]$. The BBSome is a multi-protein complex associated with IFT that is also required for the traffic of several membrane proteins into and out of the cilium [82-87]. Interestingly, the domain organizations of the BBS proteins and the IFT-A proteins closely resemble those of the canonical membrane coating complexes (COPI, COPII and Clathrin) [37,38]. Despite being involved in different intracellular trafficking pathways, all of these complexes contain numerous predicted WD-40 $\beta$-propeller and TPR $/ \alpha$-solenoid-like domains, suggesting that these systems evolved from a common ancestral trafficking machinery and may utilize similar transport mechanisms $[37,38,83]$. Intriguingly, in the case of clathrin-mediated vesicular transport, WD40 $\beta$ propeller domains are known to selectively bind unique cargo peptides [88]. It is possible that the WD40 $\beta$ propeller domains in the IFT-A complex and BBSome selectively interact with the CTSs of ciliary membrane proteins to facilitate their transport into the cilium. Further studies characterizing the IFT-A and BBSome WD40 $\beta$-propeller domains may yield insights into ciliary membrane protein targeting and traffic.

\section{Intraflagellar transport complex-cargo interactions}

Although several studies have provided indirect evidence for the association of the IFT complex with ciliary cargoes, proof of direct interactions between IFT proteins and cargoes remains scarce. One of the earliest pieces of evidence for an association between the IFT complex and ciliary cargo comes from the co-immunoprecipitation of IFT74 and IFT139 performed on the soluble fraction of Chlamydomonas flagella, which revealed that the IFT complex interacts with ciliary precursors such as dynein light chains, radial spokes, motors and tubulin [89]. Tubulin, a basic structural component of the axoneme, was also shown to undergo IFT-like movement in C. elegans sensory neurons [69]. In the following sections we discuss the various reports describing direct and indirect associations between IFT proteins and ciliary cargo.

\section{IFT88}

Several studies suggest interactions between the TPRprotein IFT88 and ciliary cargo. Co-immunoprecipitation of IFT88 from retinal extracts revealed an association with rhodopsin [90]. Furthermore, IFT88 and rhodopsin were shown to undergo similar movement within the cilia of hTERT-RPE1 cells, indicating that IFT likely plays a direct role in the transport of rhodopsin into the OS of photoreceptor cells [75]. Yeast two-hybrid studies and in vitro pulldown assays identified a Dnaj member co-chaperone, MRJ, as a direct interacting partner of IFT88 [90]. GSTtagged MRJ was also shown to associate with the photoreceptor-specific membrane protein guanylyl cyclase 1 (GC1) in a co-immunoprecipitation from bovine retinal extracts. This interaction was further confirmed by in vitro pulldown experiments using GST-MRJ and a HIStagged cytosolic fragment of GC1. It is possible that MRJ aids in the transport of ciliary GC1 by serving as an adaptor between GC1 and IFT88. As an IFT cargo, MRJ may also cooperate with HSP70 in the folding of ciliary proteins. The mode of interaction between IFT88 and these potential ciliary cargoes is currently unknown.

\section{IFT70}

IFT70 is another protein in the IFT complex that is predicted to contain TPR structure. Available evidence suggests that DYF-1, the C. elegans orthologue of IFT70, is required for the association of IFT particles with the IFT motor OSM-3. Two motors in C. elegans, heterotrimeric kinesin-2 (also called kinesin-II) and homodimeric OSM-3, coordinate to drive anterograde transport [91,92]. While both kinesin-2 and OSM-3 propel IFT in the middle segment of the cilium at a speed of $0.7 \mu \mathrm{m} / \mathrm{s}$, OSM-3 alone drives IFT in the distal segment of the cilium at an increased speed of $1.2 \mu \mathrm{m} / \mathrm{s}$ [91,93]. OSM-3 mutants (osm3) were defective in distal segment formation, while the speed of anterograde IFT in the middle segment decreased from $0.7 \mu \mathrm{m} / \mathrm{s}$ to $0.5 \mu \mathrm{m} / \mathrm{s}$ [91,93]. Interestingly, $d y f-1$ mutants exhibited a similar phenotype to osm-3 mutants and lacked OSM-3 movement, indicating that IFT70/DYF-1 is involved in docking IFT particles onto OSM-3 motors [93]. An additional study revealed that OSM-3 is in an auto-inhibitory state in vitro and hypothesized that interaction with IFT proteins is required for activation [94]. Surprisingly, however, purified DYF-1 did not activate OSM-3 in vitro [94], and it has been suggested that additional factors may be required [23].

The depletion of the zebrafish IFT70 orthologue, fleer, resulted in the loss of axonemal tubulin polyglutamylation 
and ultrastructural defects of the outer doublet microtubules (MTs) [95]. Expression of only the N-terminal catalytic domain (residues 1 to 505) of the TTLL6 tubulin polyglutamylase enzyme also resulted in the loss of axonemal polyglutamylation but, intriguingly, basal body tubulin in these cells remained polyglutamylated [95]. Thus, it is possible that the C-terminus of TTLL6 directs ciliary localization through an interaction with IFT70. As polyglutamylation is known to affect the function of motors in vivo [96-98], it is possible that the OSM3 motor is sensitive to the loss of tubulin polyglutamylation, and hence the effect of IFT70 on OSM-3 transport activity could be an indirect one [95]. Direct interaction studies between IFT70, OSM-3 type motors and the TTLL6 enzyme will likely shed light on this relationship.

\section{IFT46}

IFT46 is a well studied IFT-B core protein with an assigned function in the IFT of ODAs [24,41]. A Chlamydomonas insertional null IFT46 mutant showed reduced levels of other IFT complex proteins and flagellar assembly defects, indicating that full length IFT46 is necessary for the stability of the IFT complex [24]. A partial suppressor mutation, presumably expressing a Cterminal fragment of the IFT46 protein, alleviated most of the flagellar assembly phenotypes caused by the full depletion of IFT46, restoring wild-type IFT protein levels and normal flagellar length [24]. However, electron microscopy revealed that the axoneme of this suppressor mutant specifically lacks ODAs. This indicates that the $\mathrm{N}$-terminus of IFT46 is involved in the transport of ODAs, while the C-terminus is required for the stability of the IFT complex [24]. This notion is supported by sequence alignments of IFT46 proteins, which only show high sequence identity for the N-terminal part of IFT46 from organisms with motile cilia, likely a reflection of this domain's conserved role in ODA transport (data not shown). It was later observed that IFT46 directly binds to ODA16, an adaptor protein that bridges the IFT complex with ODAs [41,42]. Further molecular characterization of the IFT46-ODA16-ODA complex is necessary to understand how IFT46 and ODA16 specifically recognize ODAs as ciliary cargoes.

\section{The IFT-A complex}

Compared to the IFT-B complex, proteins of the IFT-A complex are not well characterized. Co-immunoprecipitation of LAP-tagged tubby like protein 3 (TULP3) from human RPE1 cell extract revealed that IFT-A proteins interact directly with TULP3 [80]. This interaction was further mapped to the IFT-A "core" complex that contains IFT140, IFT144 and IFT122 [80]. Interestingly, depletion of either IFT-A "core" components or TULP3 caused mislocalization of certain ciliary GPCRs. TULP3 contains a TUBBY domain at its $\mathrm{C}$-terminus that binds phosphoinositides [99]. A TULP3 mutant (TULP3KR) that is defective in phosphoinositide binding affected the localization of ciliary GPCRs but was still able to interact with the IFT-A complex [80]. This indicates that TULP3 bridges the IFT-A complex and ciliary GPCRs, thus aiding in ciliary GPCR transport. Further studies are needed to dissect the TULP3 interaction with IFT-A, as well as the specific role of the TUBBY domain in recognizing ciliary GPCRs $[64,100]$.

\section{Intraflagellar transport complex-motor interactions}

The interactions between IFT motors and IFT complexes are central to understanding how the bidirectional movement of IFT trains is regulated, particularly at the IFT turnaround zones at the ciliary base and tip [101]. As described above, IFT70 (with the help of additional factors) may mediate OSM-3 docking to IFT particles in C. elegans. However, the binding interactions between IFT complexes and the most evolutionarily conserved IFT motors, heterotrimeric kinesin-2 and cytoplasmic dynein 2, remain more elusive. Kinesin-2 appears to bind the IFT-A complex in C. elegans, and is only physically coupled to IFT-B and OSM-3 via the BBSome [93]. Co-immunoprecipitation experiments in vertebrate cells implicated IFT20 and IFT57 in binding kinesin-2 [45,102], and yeast two-hybrid analysis showed that IFT20 strongly interacts with both IFT57 and the KIF3B motor subunit of kinesin-2 [45]. However, these interactions were not verified in an independent study [5]. Tomographic reconstructions of in situ IFT particles revealed densities that are most likely kinesin motors connecting IFT particles to the axoneme, but the study did not identify which IFT proteins bind to the motors [32]. Live-cell fluorescence microscopy of IFT in Chlamydomonas has indicated that kinesin-2 (or at least the non-motor KAP subunit) may detach from IFT particles at the ciliary tip [103-105]. In contrast, kinesin-2 was observed to undergo retrograde transport in $C$. elegans [106]. If kinesin-2 does separate from IFT particles at the ciliary tip, this implies that kinesin-2 may ensure that only one type of motor is active at a time by inhibiting dynein 2 function during anterograde transport.

In Chlamydomonas, co-immunoprecipitation of IFT172 showed an interaction with cytoplasmic dynein 2 that was independent of IFT-A [107], and studies of temperaturesensitive mutants revealed that IFT172 is required for entry of dynein 2 into the flagellum [107,108]. Rescue of Tetrahymena IFT172 knockout cells with C-terminally truncated IFT172 constructs resulted in partial recovery of ciliary assembly and accumulation of IFT proteins at the ciliary tips, reminiscent of a retrograde IFT defect [109]. Thus, IFT172 may be divided into 
an N-terminal PD that binds the IFT-B "core" and a C-terminal $\mathrm{AD}$ that interacts with dynein 2 (Figure 1). Additionally, co-immunoprecipitation of the microtubule plus-end-tracking protein EB1 from Chlamydomonas flagellar extract pulled down IFT172 independent of both IFT-A and IFT-B [110,111], although it is unknown which domain of IFT172 mediates this interaction. If binding EB1 modulates the affinity of IFT172 to either dynein 2 or the IFT-B "core", this could contribute to the regulation of IFT turnaround at the ciliary tip. Interestingly, the partial depletion of dynein 2 from mutant Chlamydomonas flagella resulted in a compensatory increase in flagellar EB1 [112], so the two proteins may affect each other's interaction with IFT172.

\section{The BBSome: bridging IFT-A and IFT-B?}

Purification of native IFT particles from Chlamydomonas flagella revealed that IFT-A and IFT-B complexes are loosely associated [2]. Despite their weak association in vitro, components of IFT-A and IFT-B move together in C. elegans sensory cilia, indicating that additional factors may play a role in the IFT complex stability in vivo [93,113]. Surprisingly, in C. elegans bbs-7 and bbs-8 mutants, the components of IFT-A and IFT-B are carried at different speeds by the heterotrimeric kinesin- 2 and homodimeric OSM-3 motors, respectively [93]. This suggests that the BBSome, in addition to its well established function in cycling membrane proteins through cilia [82,84,114-117], may also play a role in holding IFT-A and IFT-B together in vivo [93]. This conclusion led to the proposal of the "mechanical competition" model, where the BBSome keeps the IFT-A and IFT-B complexes together resulting in IFT that proceeds at an intermediate speed [92]. However, two observations do not agree with the "mechanical competition" model. First, in Chlamydomonas flagella, the levels of BBS proteins are substoichiometric compared to IFT protein levels, and the BBSome component BBS4 undergoes IFT with only a subset of IFT particles [82]. Second, in C. elegans, a DYF-2 (IFT144 orthologue) pointmutation resulted in the accumulation of BBSomes at the base of the cilium and the absence of BBSomes inside the cilium, but IFT-A and IFT-B complexes nevertheless moved together at intermediate speeds that were similar to wild-type [113]. Interestingly, in the $d y f-2$ mutant, IFT$\mathrm{B}$ components failed to associate with the retrograde IFT machinery and thus accumulated at the ciliary tip. These observations led to the proposal of a model where the BBSome plays a role in the formation of stable IFT complexes at the base and the tip of the cilium but is not necessary for IFT complex stability during anterograde IFT [113]. In any case, both models suggest that the BBSome interacts with components of both the IFT-A and IFT-B complexes. Interestingly, in mice, BBSome component BBS1 was shown to directly interact with the IFT-A component WDR19 (IFT144 orthologue) [113]. As for the IFT-B complex, a large scale yeast two-hybrid study with C. elegans proteins revealed an interaction between the IFT-B accessory protein DYF-3 and the BBSome component BBS-7 [118]. Further studies are necessary to understand the regulatory role of the BBSome in IFT.

\section{Conclusions}

Although much is known about the overall architecture of the IFT complex and the role of IFT proteins in ciliary assembly and maintenance, molecular details concerning the distinctive roles of the 20 IFT proteins are still elusive. As pointed out in this review, it is likely that many IFT proteins possess principal domains required for IFT complex formation and auxiliary domains used to interact with ciliary cargo and motors. Functional dissection of these domains will remain the focus of extensive research in the coming years. While it is likely that highly abundant ciliary proteins such as tubulin, dynein arms and radial spokes have unique binding sites on the IFT complex, other ciliary cargo may compete via their CTS for binding to more generic cargo sites. In summary, the IFT complex contains numerous TPR and WD40 repeat domains that are expected to fulfill the task of selectively transporting a large number of ciliary proteins. Obtaining direct evidence for these interactions by means of either structural or functional studies would be a significant leap forward for the IFT field.

\section{Abbreviations \\ 5-HTR6: serotonin receptor 6; AD: auxiliary domains; CTS: ciliary targeting sequence; GC: guanylyl cyclase; GPCR: G-protein coupled receptors; \\ IFT: intraflagellar transport; NLS: nuclear localization signal; ODA: outer dynein arms; OS: outer segment; PC: polycystin; PD: principal domains; Shh: sonic hedgehog; SSTR3: somatostatin receptor 3; TPR: tetratrico peptide repeat; TRPV: Transient receptor potential vanilloid; TULP3: tubby like protein 3.}

\section{Competing interests}

The authors declare that they have no competing interests.

\section{Authors' contributions}

BDE wrote the "IFT complex-motor interactions" section. SB and EL wrote the rest of the manuscript. All the authors read and approved the final manuscript.

\section{Acknowledgements}

We thank Michael Taschner and three of the four anonymous reviewers for carefully reading and commenting on the manuscript. BDE was supported by a postdoctoral research fellowship granted by the Alexander von Humboldt Foundation.

\section{Author details}

'Department of Structural Cell Biology, Max-Planck-Institute of Biochemistry, Am Klopferspitz 18, D-82152 Martinsried, Germany. ${ }^{2}$ Department of Molecular Structural Biology, Max-Planck-Institute of Biochemistry, Am Klopferspitz 18, D-82152 Martinsried, Germany.

Received: 9 April 2013 Accepted: 5 July 2013

Published: 14 Aug 2013 


\section{References}

1. Kozminski KG, Johnson KA, Forscher P, Rosenbaum JL (1993) A motility in the eukaryotic flagellum unrelated to flagellar beating. Proc Natl Acad Sci USA 90:5519-5523

2. Cole DG, Diener DR, Himelblau AL, Beech PL, Fuster JC, Rosenbaum JL (1998) Chlamydomonas kinesin-II-dependent intraflagellar transport (IFT): IFT particles contain proteins required for ciliary assembly in Caenorhabditis elegans sensory neurons. J Cell Biol 141:993-1008

3. Piperno G, Mead K (1997) Transport of a novel complex in the cytoplasmic matrix of Chlamydomonas flagella. Proc Natl Acad Sci USA 94:4457-4462

4. Pazour GJ, Baker SA, Deane JA, Cole DG, Dickert BL, Rosenbaum JL, Witman GB, Besharse JC (2002) The intraflagellar transport protein, IFT88, is essential for vertebrate photoreceptor assembly and maintenance. J Cell Biol 157:103-113

5. Follit JA, Xu F, Keady BT, Pazour GJ (2009) Characterization of mouse IFT complex B. Cell Motil Cytoskeleton 66:457-468

6. Blacque OE, Perens EA, Boroevich KA, Inglis PN, Li C, Warner A, Khattra J, Holt RA, Ou G, Mah AK, McKay SJ, Huang P, Swoboda P, Jones SJM, Marra MA, Baillie DL, Moerman DG, Shaham S, Leroux MR (2005) Functional genomics of the cilium, a sensory organelle. Curr Biol 15:935-941

7. Bacaj T, LU Y, Shaham S (2008) The conserved proteins CHE-12 and DYF-11 are required for sensory cilium function in Caenorhabditis elegans. Genetics 178:989-1002

8. Fan ZC, Behal RH, Geimer S, Wang Z, Williamson SM, Zhang H, Cole DG, Qin $H$ (2010) Chlamydomonas IFT70/CrDYF-1 is a core component of IFT particle complex B and is required for flagellar assembly. Mol Biol Cell 21:2696-2706

9. Kunitomo $H$, lino Y (2008) Caenorhabditis elegans DYF-11, an orthologue of mammalian Traf3ip1/MIP-T3, is required for sensory cilia formation. Genes Cells 13:13-25

10. Wang Z, Fan Z-C, Williamson SM, Qin H (2009) Intraflagellar transport (IFT) protein IFT25 is a phosphoprotein component of IFT complex B and physically interacts with IFT27 in Chlamydomonas. PLOS One 4:e5384

11. Haycraft CJ, Schafer JC, Zhang Q, Taulman PD, Yoder BK (2003) Identification of CHE-13, a novel intraflagellar transport protein required for cilia formation. Exp Cell Res 284:249-261

12. Fliegauf M, Benzing T, Omran $H$ (2007) When cilia go bad: cilia defects and ciliopathies. Nat Rev Mol Cell Biol 8:880-893

13. Davis EE, Zhang Q, Liu Q, Diplas BH, Davey LM, Hartley J, Stoetzel C, Szymanska K, Ramaswami G, Logan CV, Muzny DM, Young AC, Wheeler DA, Cruz P, Morgan M, Lewis LR, Cherukuri P, Maskeri B, Hansen NF, Mullikin JC, Blakesley RW, Bouffard GG, Gyapay G, Rieger S, Tönshoff B, Kern I, Soliman NA, Neuhaus TJ, Swoboda KJ, Kayserili H et al (2011) TTC21B contributes both causal and modifying alleles across the ciliopathy spectrum. Nat Genet 43:189-196

14. Arts HH, Bongers EMHF, Mans DA, van Beersum SEC, Oud MM, Bolat E, Spruijt L, Cornelissen EAM, Schuurs-Hoeijmakers JHM, de Leeuw N, Cormier-Daire V, Brunner HG, Knoers NVAM, Roepman R (2011) C14ORF179 encoding IFT43 is mutated in Sensenbrenner syndrome. J Med Genet 48:390-395

15. Walczak-Sztulpa J, Eggenschwiler J, Osborn D, Brown DA, Emma F, Klingenberg C, Hennekam RC, Torre G, Garshasbi M, Tzschach A, Szczepanska M, Krawczynski M, Zachwieja J, Zwolinska D, Beales PL, Ropers H-H, Latos-Bielenska A, Kuss AW (2010) Cranioectodermal dysplasia, Sensenbrenner syndrome, is a Ciliopathy caused by mutations in the IFT122 Gene. Am J Hum Genet 86:949-956

16. Cavalcanti DP, Huber C, Le Quan Sang KH, Baujat G, Collins F, Delezoide AL, Dagoneau N, Le Merrer M, Martinovic J, Mello MFS, Vekemans M, Munnich A, Cormier-Daire V (2011) Mutation in IFT80 in a fetus with the phenotype of Verma-Naumoff provides molecular evidence for Jeune-Verma-Naumoff dysplasia spectrum. J Med Genet 48:88-92

17. Perrault I, Saunier S, Hanein S, Filhol E, Bizet A, Collins F, Salih M, Silva E, Baudouin V, Oud M, Shannon N, Le Merrer M, Pietrement C, Beales P, Arts H, Munnich A, Kaplan J, Antignac C, Cormier Daire V, Rozet JM (2012) Mainzer-Saldino syndrome is a ciliopathy caused by mutations in the IFT140 gene. Cilia 1(Suppl 1):O28

18. Rosenbaum JL, Witman GB (2002) Intraflagellar transport. Nat Rev Mol Cell Biol 3:813-825

19. Beales PL, Bland E, Tobin JL, Bacchelli C, Tuysuz B, Hill J, Rix S, Pearson CG, Kai M, Hartley J (2007) IFT80, which encodes a conserved intraflagellar transport protein, is mutated in Jeune asphyxiating thoracic dystrophy. Nat Genet 39:727-729
20. Bredrup C, Saunier S, Oud MM, Fiskerstrand T, Hoischen A, Brackman D, Leh SM, Midtbø M, Filhol E, Bole-Feysot C, Nitschké P, Gilissen C, Haugen $\mathrm{OH}$ Sanders J-SF, Stolte-Dijkstra I, Mans DA, Steenbergen EJ, Hamel BCJ, Matignon M, Pfundt R, Jeanpierre C, Boman H, Rødahl E, Veltman JA Knappskog PM, Knoers NVAM, Roepman R, Arts HH (2011) Ciliopathies with skeletal anomalies and renal insufficiency due to mutations in the IFT-A gene WDR19. Am J Hum Genet 89:634-643

21. Gilissen $C$, Arts $H H$, Hoischen A, Spruijt L, Mans DA, Arts P, van Lier B, Steehouwer M, van Reeuwijk J, Kant SG, Roepman R, Knoers NVAM, Veltman JA, Brunner HG (2010) Exome sequencing identifies WDR35 variants involved in Sensenbrenner syndrome. Am J Hum Genet 87:418-423

22. Badano JL, Mitsuma N, Beales PL (2006) The Ciliopathies: an emerging class of human genetic disorders. Annu Rev Genomics Hum Genet 7:125-148

23. Ou G, Koga M, Blacque OE, Murayama T, Ohshima Y, Schafer JC, Li C, Yoder BK, Leroux MR, Scholey JM (2007) Sensory ciliogenesis in Caenorhabditis elegans: assignment of IFT components into distinct modules based on transport and phenotypic profiles. Mol Biol Cell 18:1554-1569

24. Hou Y, Qin H, Follit JA, Pazour GJ, Rosenbaum JL, Witman GB (2007) Functional analysis of an individual IFT protein: IFT46 is required for transport of outer dynein arms into flagella. J Cell Biol 176:653-665

25. Lucker BF, Miller MS, Dziedzic SA, Blackmarr PT, Cole DG (2010) Direct interactions of intraflagellar transport complex B proteins IFT88, IFT52, and IFT46. J Biol Chem 285:21508-21518

26. Richey EA, Qin H (2012) Dissecting the sequential assembly and localization of Intraflagellar transport particle complex B in Chlamydomonas. PLoS One 7:e43118

27. Kobayashi T, Gengyo-Ando K, Ishihara T, Katsura I, Mitani S (2007) IFT-81 and IFT-74 are required for intraflagellar transport in C. elegans. Genes Cells 12:593-602

28. Brazelton WJ, Amundsen CD, Silflow CD, Lefebvre PA (2001) The bld1 mutation identifies the Chlamydomonas OSM-6 homolog as a gene required for flagellar assembly. Curr Biol 11:1591-1594

29. Adhiambo C, Blisnick T, Toutirais G, Delannoy E, Bastin P (2009) A novel function for the atypical small $G$ protein Rab-like 5 in the assembly of the trypanosome flagellum. J Cell Sci 122:834-841

30. Pazour G, Dickert BL, Vucica Y, Seeley ES, Rosenbaum JL, Witman GB, Cole DG (2000) Chlamydomonas IFT88 and its mouse homologue, polycystic kidney disease gene Tg737, are required for assembly of cilia and flagella. J Cell Biol 151:709-718

31. Tsujikawa M, Malicki J (2004) Intraflagellar transport genes are essential for differentiation and survival of vertebrate sensory neurons. Neuron 42:703-716

32. Pigino G, Geimer S, Lanzavecchia S, Paccagnini E, Cantele F, Diener DR, Rosenbaum JL, Lupetti P (2009) Electron-tomographic analysis of intraflagellar transport particle trains in situ. J Cell Biol 187:135-148

33. Bhogaraju S, Taschner M, Morawetz M, Basquin C, Lorentzen E (2011) Crystal structure of the intraflagellar transport complex 25/27. EMBO J 30:1907-1918

34. Lucker BF, Behal RH, Qin H, Siron LC, Taggart WD, Rosenbaum JL, Cole DG (2005) Characterization of the intraflagellar transport complex B core direct interaction of the IFT81 and IFT74/72 subunits. J Biol Chem 280:27688-27696

35. Taschner M, Bhogaraju S, Vetter M, Morawetz M, Lorentzen E (2011) Biochemical mapping of interactions within the intraflagellar transport (IFT) B core complex. J Biol Chem 286:26344-26352

36. Cole DG (2003) The intraflagellar transport machinery of Chlamydomonas reinhardtii. Traffic 4:435-442

37. Jékely G, Arendt D (2006) Evolution of intraflagellar transport from coated vesicles and autogenous origin of the eukaryotic cilium. Bioessays 28:191-198

38. van Dam TJP, Townsend MJ, Turk M, Schlessinger A, Sali A, Field MC, Huynen MA (2013) Evolution of modular intraflagellar transport from a coatomer-like progenitor. Proc Natl Acad Sci USA 110:6943-6948

39. Taschner M, Bhogaraju S, Lorentzen E (2012) Architecture and function of IFT complex proteins in ciliogenesis. Differentiation 83:S12-S22

40. Soding J, Biegert A, Lupas AN (2005) The HHpred interactive server for protein homology detection and structure prediction. Nucleic Acids Res 33(Web Server):W244-W248

41. Ahmed NT, Gao C, Lucker BF, Cole DG, Mitchell DR (2008) ODA16 aids axonemal outer row dynein assembly through an interaction with the intraflagellar transport machinery. J Cell Biol 183:313-322 
42. Ahmed NT, Mitchell DR (2005) ODA16p, a Chlamydomonas flagellar protein needed for dynein assembly. Mol Biol Cell 16:5004-5012

43. Keady BT, Le YZ, Pazour GJ (2011) IFT20 is required for opsin trafficking and photoreceptor outer segment development. Mol Biol Cell 22:921-930

44. Omori Y, Zhao C, Saras A, Mukhopadhyay S, Kim W, Furukawa T, Sengupta P, Veraksa A, Malicki J (2008) Elipsa is an early determinant of ciliogenesis that links the IFT particle to membrane-associated small GTPase Rab8. Nat Cell Biol 10:437-444

45. Baker SA, Freeman K, Luby-Phelps K, Pazour GJ, Besharse JC (2003) IFT20 links Kinesin II with a mammalian intraflagellar transport complex that is conserved in motile flagella and sensory cilia. J Biol Chem 278:34211-34218

46. Keady BT, Samtani R, Tobita K, Tsuchya M, San Agustin JT, Follit JA, Jonassen JA, Subramanian R, Lo CW, Pazour GJ (2012) IFT25 links the signaldependent movement of hedgehog components to intraflagellar transport. Dev Cell 22:940-951

47. Emanuelsson O (2002) Predicting protein subcellular localisation from amino acid sequence information. Brief Bioinform 3:361-376

48. Gilula NB, Satir P (1972) The ciliary necklace: a ciliary membrane specialization. J Cell Biol 53:494-509

49. Reiter JF, Blacque OE, Leroux MR (2012) The base of the cilium: roles for transition fibres and the transition zone in ciliary formation, maintenance and compartmentalization. EMBO Rep 13:608-618

50. Breslow DK, Nachury MV (2011) Primary cilia: how to keep the riff-raff in the plasma membrane. Curr Biol 21:R434-R436

51. Kee HL, Dishinger JF, Lynne Blasius T, Liu C-J, Margolis B, Verhey KJ (2012) A size-exclusion permeability barrier and nucleoporins characterize a ciliary pore complex that regulates transport into cilia. Nat Cell Biol 14:431-437

52. Francis SS, Sfakianos J, Lo B, Mellman I (2011) A hierarchy of signals regulates entry of membrane proteins into the ciliary membrane domain in epithelial cells. J Cell Biol 193:219-233

53. Geimer S, Melkonian M (2004) The ultrastructure of the Chlamydomonas reinhardtii basal apparatus: identification of an early marker of radial asymmetry inherent in the basal body. J Cell Sci 117:2663-2674

54. Craige B, Tsao C-C, Diener DR, Hou Y, Lechtreck K-F, Rosenbaum JL, Witman GB (2010) CEP290 tethers flagellar transition zone microtubules to the membrane and regulates flagellar protein content. J Cell Biol 190:927-940

55. Williams CL, Li C, Kida K, Inglis PN, Mohan S, Semenec L, Bialas NJ, Stupay RM, Chen N, Blacque OE, Yoder BK, Leroux MR (2011) MKS and NPHP modules cooperate to establish basal body/transition zone membrane associations and ciliary gate function during ciliogenesis. J Cell Biol 192:1023-1041

56. Hu Q, Milenkovic L, Jin H, Scott MP, Nachury MV, Spiliotis ET, Nelson WJ (2010) A septin diffusion barrier at the base of the primary cilium maintains ciliary membrane protein distribution. Science 329:436-439

57. Pazour GJ, Agrin N, Leszyk J, Witman GB (2005) Proteomic analysis of a eukaryotic cilium. J Cell Biol 170:103-113

58. Pazour GJ, Bloodgood RA (2008) Targeting proteins to the ciliary membrane. Curr Top Dev Biol 85:115-149

59. Dwyer ND, Adler CE, Crump JG, L'Etoile ND, Bargmann Cl (2001) Polarized dendritic transport and the AP-1 $\mu 1$ clathrin adaptor UNC-101 localize odorant receptors to olfactory cilia. Neuron 31:277-287

60. Corbit KC, Aanstad P, Singla V, Norman AR, Stainier DYR, Reiter JF (2005) Vertebrate Smoothened functions at the primary cilium. Nature 437:1018-1021

61. Palczewski K, Kumasaka T, Hori T, Behnke C, Motoshima H, Fox BA, Trong IL, Teller DC, Okada T, Stenkamp RE, Yamamoto M, Miyano M (2000) Crystal structure of rhodopsin: a G protein-coupled receptor. Science 289:733-734

62. Berbari NF, Johnson AD, Lewis JS, Askwith CC, Mykytyn K (2008) Identification of ciliary localization sequences within the third intracellular loop of G protein-coupled receptors. Mol Biol Cell 19:1540-1547

63. Nagata A, Hamamoto A, Horikawa M, Yoshimura K, Takeda S, Saito Y (2013) Characterization of ciliary targeting sequence of rat melanin-concentrating hormone receptor 1. Gen Comp Endocrinol 188:159-165

64. Mukhopadhyay S, Wen X, Ratti N, Loktev A, Rangell L (2013) The ciliary G-protein-coupled receptor Gpr161 negatively regulates the sonic hedgehog pathway via CAMP signaling. Cell 152:210-223

65. Tam BM, Moritz OL, Hurd LB, Papermaster DS (2000) Identification of an outer segment targeting signal in the $\mathrm{COOH}$ terminus of rhodopsin using transgenic Xenopus laevis. J Cell Biol 151:1369-1380

66. Sung CH, Makino C, Baylor D, Nathans J (1994) A rhodopsin gene mutation responsible for autosomal dominant retinitis pigmentosa results in a protein that is defective in localization to the photoreceptor outer segment. J Neurosci 14:5818-5833

67. Geng L, Okuhara D, Yu Z, Tian X, Cai Y, Shibazaki S, Somlo S (2006) Polycystin-2 traffics to cilia independently of polycystin-1 by using an N-terminal RVxP motif. J Cell Sci 119:1383-1395

68. Ward HH, Brown-Glaberman U, Wang J, Morita Y, Alper SL, Bedrick EJ, Gattone VH, Deretic D, Wandinger-Ness A (2011) A conserved signal and GTPase complex are required for the ciliary transport of polycystin-1. Mol Biol Cell 22:3289-3305

69. Hao L, Thein M, Brust-Mascher I, Civelekoglu-Scholey G, Lu Y, Acar S, Prevo B, Shaham S, Scholey JM (2011) Intraflagellar transport delivers tubulin isotypes to sensory cilium middle and distal segments. Nat Cell Biol 13:790-798

70. Scholey JM (2012) Kinesin-2 motors transport IFT-particles, dyneins and tubulin subunits to the tips of Caenorhabditis elegans sensory cilia: relevance to vision research? Vision Res 75:44-52

71. Dishinger JF, Kee HL, Jenkins PM, Fan S, Hurd TW, Hammond JW, Truong YN-T, Margolis B, Martens JR, Verhey KJ (2010) Ciliary entry of the kinesin-2 motor KIF17 is regulated by importin- $\beta 2$ and RanGTP. Nat Cell Biol 12:703-710

72. Fan S, Whiteman EL, Hurd TW, McIntyre JC, Dishinger JF, Liu CJ, Martens JR, Verhey KJ, Sajjan U, Margolis B (2011) Induction of Ran GTP drives ciliogenesis. Mol Biol Cell 22:4539-4548

73. Hurd TW, Fan S, Margolis BL (2011) Localization of retinitis pigmentosa 2 to cilia is regulated by Importin 2. J Cell Sci 124:718-726

74. Wolfrum U, Schmitt A (2000) Rhodopsin transport in the membrane of the connecting cilium of mammalian photoreceptor cells. Cell Motil Cytoskeleton 46:95-107

75. Trivedi D, Colin E, Louie CM, Williams DS (2012) Live-cell imaging evidence for the ciliary transport of Rod photoreceptor Opsin by Heterotrimeric Kinesin-2. J Neurosci 32:10587-10593

76. Marszalek JR, Liu X, Roberts EA, Chui D, Marth JD, Williams DS, Goldstein LSB (2000) Genetic evidence for selective transport of Opsin and Arrestin by Kinesin-II in mammalian photoreceptors. Cell 102:175-187

77. Qin H, Burnette DT, Bae Y-K, Forscher P, Barr MM, Rosenbaum JL (2005) Intraflagellar transport is required for the vectorial movement of TRPV channels in the ciliary membrane. Curr Biol 15:1695-1699

78. Huang K, Diener DR, Mitchell A, Pazour GJ, Witman GB, Rosenbaum JL (2007) Function and dynamics of PKD2 in Chlamydomonas reinhardtii flagella. J Cell Biol 179:501-514

79. Shih SM, Engel BD, Kocabas F, Bilyard T, Gennerich A, Marshall WF, Yildiz A (2013) Intraflagellar transport drives flagellar surface motility. elife 2:e00744

80. Mukhopadhyay S, Wen X, Chih B, Nelson CD, Lane WS, Scales SJ, Jackson PK (2010) TULP3 bridges the IFT-A complex and membrane phosphoinositides to promote trafficking of $\mathrm{G}$ protein-coupled receptors into primary cilia. Genes Dev 24:2180-2193

81. Liem KF, Ashe A, He M, Satir P, Moran J, Beier D, Wicking C, Anderson KV (2012) The IFT-A complex regulates Shh signaling through cilia structure and membrane protein trafficking. J Cell Biol 197:789-800

82. Lechtreck K-F, Johnson EC, Sakai T, Cochran D, Ballif BA, Rush J, Pazour GJ, Ikebe M, Witman GB (2009) The Chlamydomonas reinhardtii BBSome is an IFT cargo required for export of specific signaling proteins from flagella. J Cell Biol 187:1117-1132

83. Jin H, White SR, Shida T, Schulz S, Aguiar M, Gygi SP, Bazan JF, Nachury MV (2010) The conserved Bardet-Biedl syndrome proteins assemble a coat that traffics membrane proteins to cilia. Cell 141:1208-1219

84. Berbari NF, Lewis JS, Bishop GA, Askwith CC, Mykytyn K (2008) Bardet-Bied syndrome proteins are required for the localization of $\mathrm{G}$ protein-coupled receptors to primary cilia. Proc Natl Acad Sci USA 105:4242-4246

85. Zhang Q, Seo S, Bugge K, Stone EM, Sheffield VC (2012) BBS proteins interact genetically with the IFT pathway to influence SHH-related phenotypes. Hum Mol Genet 21:1945-1953

86. Nachury MV, Loktev AV, Zhang Q, Westlake CJ, Peränen J, Merdes A Slusarski DC, Scheller RH, Bazan JF, Sheffield VC, Jackson PK (2007) A core complex of BBS proteins cooperates with the GTPase Rab8 to promote ciliary membrane biogenesis. Cell 129:1201-1213

87. Blacque OE, Michael RJ, Chunmei L, Jonathan M, Leroux MR (2004) Loss of C. elegans BBS-7 and BBS-8 protein function results in cilia defects and compromised intraflagellar transport. Genes Dev 18:1630-1642

88. ter Haar E, Harrison SC, Kirchhausen T (2000) Peptide-in-groove interactions link target proteins to the $\beta$-propeller of clathrin. Proc Natl Acad Sci USA 97:1096-1100 
89. Qin H, Diener DR, Geimer S, Cole DG, Rosenbaum JL (2004) Intraflagellar transport (IFT) cargo: IFT transports flagellar precursors to the tip and turnover products to the cell body. J Cell Biol 164:255-266

90. Bhowmick R, Li M, Sun J, Baker SA, Insinna C, Besharse JC (2009) Photoreceptor IFT complexes containing chaperones, guanylyl cyclase 1 and rhodopsin. Traffic 10:648-663

91. Snow JJ, Ou G, Gunnarson AL, Walker MRS, Zhou HM, Brust-Mascher I, Scholey JM (2004) Two anterograde intraflagellar transport motors cooperate to build sensory cilia on C. elegans neurons. Nat Cell Biol 6:1109-1113

92. Pan X, Ou G, Civelekoglu-Scholey G, Blacque OE, Endres NF, Tao L, Mogilner A, Leroux MR, Vale RD, Scholey JM (2006) Mechanism of transport of IFT particles in C. elegans cilia by the concerted action of kinesin-II and OSM-3 motors. J Cell Biol 174:1035-1045

93. Ou G, Blacque OE, Snow JJ, Leroux MR, Scholey JM (2005) Functional coordination of intraflagellar transport motors. Nature 436:583-587

94. Imanishi M, Endres NF, Gennerich A, Vale RD (2006) Autoinhibition regulates the motility of the C. elegans intraflagellar transport motor OSM-3. J Cell Biol 174:931-937

95. Pathak N, Obara T, Mangos S, Liu Y, Drummond IA (2007) The Zebrafish fleer gene encodes an essential regulator of Cilia tubulin polyglutamylation. Mol Biol Cell 18:4353-4364

96. Ikegami K, Heier RL, Taruishi M, Takagi H, Mukai M, Shimma S, Taira S, Hatanaka K, Morone N, Yao I, Campbell PK, Yuasa S, Janke C, MacGregor GR, Setou M (2007) Loss of tubulin polyglutamylation in ROSA22 mice is associated with abnormal targeting of KIF1A and modulated synaptic function. Proc Natl Acad Sci USA 104:3213-3218

97. Kubo T, Yanagisawa H-A, Yagi T, Hirono M, Kamiya R (2010) Tubulin polyglutamylation regulates axonemal motility by modulating activities of inner-arm dyneins. Curr Biol 20:441-445

98. Kubo T, Yagi T, Kamiya R (2012) Tubulin polyglutamylation regulates flagellar motility by controlling a specific inner-arm dynein that interacts with the dynein regulatory complex. Cytoskeleton 69:1059-1068

99. Santagata S, Boggon TJ, Baird CL, Gomez CA, Zhao J, SHan WS, Myszka DG Shapiro L (2001) G-Protein signaling through tubby proteins. Science 292:2041-2050

100. Mukhopadhyay S, Jackson PK (2013) Cilia, tubby mice, and obesity. Cilia 2:1

101. Iomini C, Babaev-Khaimov V, Sassaroli M, Piperno G (2001) Protein particles in Chlamydomonas flagella undergo a transport cycle consisting of four phases. J Cell Biol 153:13-24

102. Krock BL, Perkins BD (2008) The intraflagellar transport protein IFT57 is required for cilia maintenance and regulates IFT-particle-kinesin-II dissociation in vertebrate photoreceptors. J Cell Sci 121:1907-1915

103. Engel BD, Ludington WB, Marshall WF (2009) Intraflagellar transport particle size scales inversely with flagellar length: revisiting the balance-point length control model. J Cell Biol 187:81-89

104. Engel BD, Lechtreck K-F, Sakai T, Ikebe M, Witman GB, Marshall WF (2009) Total internal reflection fluorescence (TIRF) microscopy of chlamydomonas flagella. Methods Cell Biol 93:157-177

105. Lechtreck KF (2013) In vivo imaging of IFT in Chlamydomonas flagella. Methods Enzymol 524:265-284

106. Signor D, Wedaman KP, Orozco JT, Dwyer ND, Bargmann Cl, Rose LS, Scholey JM (1999) Role of a class DHC1b dynein in retrograde transport of IFT motors and IFT raft particles along cilia, but not dendrites, in chemosensory neurons of living Caenorhabditis elegans. J Cell Biol 147:519530

107. Pedersen LB, Geimer S, Rosenbaum JL (2006) Dissecting the molecular mechanisms of intraflagellar transport in chlamydomonas. Curr Biol 16:450-459

108. Williamson SM, Silva DA, Richey E, Qin H (2012) Probing the role of IFT particle complex $A$ and $B$ in flagellar entry and exit of IFT-dynein in Chlamydomonas. Protoplasma 249:851-856

109. Tsao CC, Gorovsky MA (2008) Different effects of tetrahymena IFT172 domains on anterograde and retrograde intraflagellar transport. Mol Biol Cell 19:1450-1461

110. Pedersen LB, Miller MS, Geimer S, Jeffery LM, Rosenbaum JL, Cole DG (2005) Chlamydomonas IFT172 is encoded by FLA11, interacts with CrEB1, and regulates IFT at the flagellar tip. Curr Biol 15:262-266

111. Pedersen LB, Geimer S, Sloboda RD, Rosenbaum JL (2003) The microtubule plus end-tracking protein EB1 is localized to the flagellar tip and basal bodies in Chlamydomonas reinhardtii. Curr Biol 13:1969-1974
112. Engel $B D$, Ishikawa $H$, Wemmer KA, Geimer $S$, Wakabayashi K-I, Hirono $M$ Craige B, Pazour GJ, Witman GB, Kamiya R, Marshall WF (2012) The role of retrograde intraflagellar transport in flagellar assembly, maintenance, and function. J Cell Biol 199:151-167

113. Wei Q, Zhang Y, Li Y, Zhang Q, Ling K, Hu J (2012) The BBSome controls IFT assembly and turnaround in cilia. Nat Cell Biol 14:950-957

114. Lechtreck KF, Brown JM, Sampaio JL, Craft JM, Shevchenko A, Evans JE, Witman GB (2013) Cycling of the signaling protein phospholipase D through cilia requires the BBSome only for the export phase. J Cell Biol 201:249-261

115. Domire JS, Green JA, Lee KG, Johnson AD, Askwith CC, Mykytyn K (2010) Dopamine receptor 1 localizes to neuronal cilia in a dynamic process that requires the Bardet-Biedl syndrome proteins. Cell Mol Life Sci 68:2951-2960

116. Seo S, Zhang Q, Bugge K, Breslow DK, Searby CC, Nachury MV, Sheffield VC (2011) A novel protein LZTFL1 regulates ciliary trafficking of the BBSome and Smoothened. PLoS Genet 7:e1002358

117. Zhang Q, Nishimura D, Seo S, Vogel T, Morgan DA, Searby C, Bugge K, Stone EM, Rahmouni K, Sheffield VC (2011) Bardet-Biedl syndrome 3 (Bbs3) knockout mouse model reveals common BBS-associated phenotypes and Bbs3 unique phenotypes. Proc Natl Acad Sci USA 108:20678-20683

118. Li S, Armstrong CM, Bertin N, Ge H, Milstein S, Boxem M, Vidalain P-O, Han J-DJ, Chesneau A, Hao T, Goldberg DS, Li N, Martinez M, Rual J-F, Lamesch P, Xu L, Tewari M, Wong SL, Zhang LV, Berriz GF, Jacotot L, Vaglio P, Reboul J, Hirozane-Kishikawa T, Li Q, Gabel HW, Elewa A, Baumgartner B, Rose DJ, Yu H et al (2004) A map of the interactome network of the metazoan C. elegans. Science 303:540-543

10.1186/2046-2530-2-10

Cite this article as: Bhogaraju et al: Intraflagellar transport complex structure and cargo interactions. Cilia 2013, 2:10

\section{Submit your next manuscript to BioMed Central and take full advantage of:}

- Convenient online submission

- Thorough peer review

- No space constraints or color figure charges

- Immediate publication on acceptance

- Inclusion in PubMed, CAS, Scopus and Google Scholar

- Research which is freely available for redistribution

Submit your manuscript at www.biomedcentral.com/submit 